\title{
Effects of School Starting Age on the Family
}

\author{
Rasmus Kløve Landersø \\ Helena Skyt Nielsen \\ Marianne Simonsen
}

\begin{abstract}
This paper investigates intra-family spillovers from the focal child's timing of school start. We first show how school starting age affects the timing of subsequent educational transitions. Exploiting quasi-random variation in school starting age induced by date of birth, we then document effects on parental outcomes. At child age seven, for example, being one year older at school start increases maternal employment with four percentage points; at child age 15, it increases the likelihood that parents still cohabit with eight percentage points. Our results also indicate that later school start for the focal child improves older siblings’ academic performance.
\end{abstract}

JEL: I21, J12.

Keywords: marital capital, marital dissolution, educational transition, regression discontinuity, spillover effects.

Rasmus Kløve Landersø is a senior researcher at the Rockwool Foundation Research Unit. Helena Skyt Nielsen is a professor of economics at Aarhus University (hnielsen@econ.au.dk). Marianne Simonsen is a professor of economics at Aarhus University. This paper uses confidential data from Statistics Denmark. Access is possible from the Rockwool Foundation Research Unit in Denmark after signing a data security

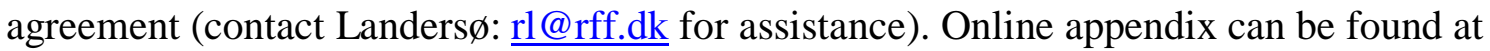
http://jhr.uwpress.org/. We appreciate comments from three anonymous referees as well as 
Jon Guryan, Eskil Heinesen, Maria Knoth Humlum, Jan Rose Skaksen, Lars Skipper, and Emma Tominey as well as from seminar participants at the University of Bergen, Lund University, and Paris School of Economics and conference participants at the University of Notre Dame - London Global Gateway Economics of the Family Conference, 2016; the ${ }^{\text {nd }}$ the Family and Education Workshop 2016; ESPE 2016; and EALE 2016. Financial support from CIRRAU (Simonsen) is gratefully acknowledged. The usual disclaimer applies. 


\section{Introduction}

Education is one of the most important investments in children made by parents and society as a whole. School start is therefore a pivotal point in the life of the individual child, and the consequences of school starting age (henceforth SSA) have been investigated by many researchers. Children perform better in school, both in terms of grades (e.g. Bedard and Dhuey 2006; Cook and Kang 2016; Dhuey et al. 2017) and behavior (e.g. Dee and Sievertsen 2018), when SSA is higher. Yet these short-term effects do not arise from SSA per se but rather from the persistent age difference between children who start school at different ages. The long-term impact of higher SSA is generally found to be miniscule (e.g. Black, Devereux, and Salvanes 2011; Fredriksson and Öckert 2013; Dustmann, Puhani, and Schönberg 2017; Landersø, Nielsen, and Simonsen 2017).

Children’s school start is, however, not only important in terms of their own human capital accumulation; it is also classified as a major stressful life event-a life change unit — both for the children in question as well as for their families (Holmes and Rahe 1967). This paper asks whether a policy manipulable variable, such as SSA (and consequently the timing of a child's educational trajectory), has spillover effects to family members other than the targeted child, thereby affecting, for example, family stability and sibling school performance. In other words, when parents actively make changes to when and how they invest in one child given the policy-environment they face, do they - as we would expect from theory - thereby improve the family's outcomes in other dimensions? We will address this key question by estimating the causal effect of SSA on parents' and siblings' outcomes. To the best of our knowledge, we are the first to do this.

Our empirical analysis exploits exogenous variation in SSA generated by administrative rules to circumvent the issue that SSA may correlate with unobservable individual and family characteristics. We make use of the fact that Danish children typically 
start first grade in the calendar year in which they turn seven, which gives rise to a fuzzy regression discontinuity design; a strategy now widely used in the literature on school starting age. By comparing the families of children born in December with families of children born in January, we investigate the effects of focal children starting grade 1 at age 6.6 compared to 7.6. Our analysis uses full population Danish register-based data for focal children born in the period 1986-2000 with information on exact birth dates, family and sibling outcomes, and a rich set of background characteristics.

We show how a child's SSA has direct consequences for their other family members. In the context of this paper, a higher SSA implies that the child spends an extra year in public childcare instead of going to school. ${ }^{1}$ Delaying school start by one year improves parental relationship stability and increases maternal employment while the child is of school age. At child age seven, for example, being one year older at school start increases maternal employment with four percentage points relative to a mean of just below $80 \%$. During child ages 15-18, being one year older at school start increases the likelihood that the parents continue their relationship with eight percentage points relative to a mean of just above $60 \%$. We observe that, for the most part, the effects for parents' marital stability persist. For maternal employment, however, the effects in the years following school start are different in nature. Here, we instead find a transitory effect around school start, both at the extensive and intensive labor supply margin, likely because child maturity at school start eases the child's transition from daycare to school thereby reducing within-family constraints, which may otherwise have hindered maternal labor supply at that point in time. ${ }^{2}$

While none of the effects for parental outcomes persists after age 18-20 of the focal child, changes in parental outcomes could still be important in the longer run because they reflect redistribution of resources within the family to counteract the impact of school start. We indeed find that postponing the school start of one child improves specific 
dimensions of the academic achievements of older siblings who are close to their final exam around the school start of the focal child. Grades associated with repetitive learning based on memorization (so-called rote learning), such as basic arithmetic and grammar (where parents can teach to the test), improve substantially, whereas grades associated with tasks that are more complex and general knowledge (e.g., essays and text analysis) are unaffected. Hence, delaying the school start of a younger sibling allows parents to redirect resources towards the dimensions in older siblings’ upcoming exams that are most easily improved.

Our results have three important implications. First, they emphasize that educational policies and public investments may have effects beyond their primary objectives and those directly affected by the policy; see, for example, Garces, Duncan, and Currie (2002), Nicoletti and Rabe (2016), Joensen and Nielsen (2018), and Qureshi (2018; forthcoming). Not only may the level of public investments in schools make parents adjust their behavior, as found by Cascio and Schanzenbach (2013), Gelber and Isen (2013), and Pop-Eleches and Urquiola (2013), our results also show that the timing of public investments matters and shapes parental behavior as well. ${ }^{3}$ As such, our paper speaks to the broader family economics literature, including the seminal papers by Becker and Tomes $(1976,1979)$ that are concerned with within-family variation in child outcomes and studies on how parents optimally and under constraints choose to allocate investments across different periods (Cunha and Heckman 2007). Second, our results have bearing for the interpretation of the existing estimates of the consequences of SSA for child outcomes, as the behavioral adjustments of parents and siblings may be some of the mechanisms behind these results. A reallocation of resources to siblings, for example, is likely to dampen any positive long-run effects of SSA on the focal child. But we also detect a delay in marital disruption, which may or may not improve outcomes of the focal child, depending on the quality of the prolonged relationship. Finally, our findings illustrate that within-family spillover of major stressful life 
events is not only present in extremely disadvantaged families, such as families with incarcerated fathers (Andersen and Wildeman 2014) or disabled children (e.g. Kvist, Nielsen, and Simonsen 2013; Breining 2014; Black et al. 2017).

The paper is structured as follows: Section II presents the institutional background and conceptual framework, and Section III describes our empirical methodology. Section IV presents our data and Section V presents the results. Finally, Section VI concludes.

\section{Background}

This section presents three cornerstones to our empirical analysis and findings. We first outline the institutional settings relevant for school starting age in Denmark. Second, we illustrate how the timing of a child's educational cycle is strongly linked to its age at school start. And finally, we introduce the framework linking school start of one child to the family’s life.

\section{A. Institutional Settings Relevant for School Starting Age (SSA)}

Our empirical analysis will exploit plausibly exogenous, institutionally induced variation in SSA. During the period of relevance for this study, Danish law stipulated that education was compulsory from the calendar year of the child's $7^{\text {th }}$ birthday and until completion of $9^{\text {th }}$ grade. ${ }^{4}$ This school system is fortunate for a study like ours because there is no automatic relationship between SSA and minimum required years of completed schooling, as is the case in the US and UK systems due to minimum school leaving ages. Pupils receive teacher-assessed grades in grades 8 and 9 and take compulsory exit exams in a number of subjects at the end of grade 9. Further education is voluntary and may follow a more academic path (starting with high school) or a vocational path (vocational school). ${ }^{5}$ 
The year before entering first grade, children can enroll in Kindergarten, ${ }^{6}$ which typically is located in the same building as the school (and was voluntary during the period relevant for this study). Kindergarten, compulsory schooling from grades 1-9, upper secondary school and even most higher education programs are free of charge. Furthermore, already at age four, the vast majority (98\% in 2004; see statistikbanken.dk) of children are enrolled in some form of public daycare, which is heavily subsidized. ${ }^{7}$

The transition from daycare to Kindergarten as well as the transition from Kindergarten to first grade may be challenging for the child and the family. In daycare the average staff-to-child ratio is 1:7, and the institutions provide care, education and opportunities to play. Activities are child-centered rather than based on a basic skills curriculum. ${ }^{8}$ While the main focus in daycare is on socialization, Kindergarten involves a skills curriculum and a school environment with higher demands and gradually more focus on educational activities. There are typically one social educator and a part-time assistant per Kindergarten class (maximum class size is 28 pupils). After Kindergarten, children continue in first grade with the same classmates and in the same physical surroundings, while they are now taught by educated teachers who exercise more control and have higher demands in terms of behavior and performance.

Parents and administrators have considerable leeway when deciding when children should start school. ${ }^{9}$ Therefore, SSA is not random and is most likely affected by a range of factors that may also correlate with the child's outcomes and those of their family. Factors like maturity, school readiness, behavior in childcare, and parents’ preferences may affect the timing of school start.

To address the consequences of SSA, our empirical analysis exploits that the formal age at school start is defined by birth year and employs a strategy similar to Elder (2010), Evans et al. (2010), Black, Devereux, and Salvanes (2011), and Fredriksson and 
Öckert (2013). January 1 is the relevant cutoff point: according to administrative rules, children born just before this date are supposed to start in school in one year and children born just after in the subsequent year. Some parents of children born close to this cutoff date choose to manipulate their children’s actual SSA: late-year children are more likely to postpone school start by a year, whereas early-year children are more likely to start school one year earlier than stipulated. Consequently, some children born in December will start school one year later than they are "supposed” to-approximately at age 7.6 —-whereas the remainder of the children born in December will start around age 6.6. Likewise, some children born in January will start school at age 6.6, which is one year earlier than the law stipulates, while the remainder will start school at age 7.6. SSA for children born around the cutoff date is effectively reduced to a binary outcome: children start at age either 6.6 or $7.6 .^{10}$ As described in the beginning of this section, the alternative to starting school is to spend an additional year in daycare care setting. Only a negligible proportion of children are not in daycare immediately before school start.

If children born around the cutoff are 7.6 years old at school start, we label them "old-for-grade." Figure 1 shows the fraction of children who are old-for-grade by date of birth. There is a smooth upward trend in the fraction of old-for-grade children in December followed by a large discontinuity of approximately 20 percentage points around January $1 .^{11}$ $<$ FIGURE 1 APPROXIMATELY HERE $>$

\section{B. Timing of the Education Cycle}

Our research design exploits quasi-random shifts in the timing of transitions into school. There is, however, a strong link between the timing of the transition into school and subsequent transitions in the education system. Figure 2 illustrates the relationship in the context of this paper. The figure shows how, among Danish school children who enroll in $1^{\text {st }}$ 
grade during the calendar year when they turn 7 (which is most children), virtually all have left lower secondary school and started upper secondary school during the calendar year when they turn 17. This transition occurs one year later for individuals who started $1^{\text {st }}$ grade during the calendar year when they turned eight and one year earlier for individuals who started $1^{\text {st }}$ grade the calendar year they turned six. Figure 2 shows that postponing school start by one year implies postponing graduation by one year and so forth also college entry and moving away from home. Hence, a shock to SSA constitutes a shock to the timing of several of the critical school transitions that potentially stress the entire family.

<FIGURE 2 APPROXIMATELY HERE $>$

\section{Conceptual Framework and Initial Descriptive Evidence: The Link between School Starting Age and Outcomes of the Family}

Economists have long been concerned with how access to childcare affects parental (maternal) labor supply; see for example Gelbach (2002), Havnes and Mogstad (2011), Fitzpatrick (2012), Cascio, Haider, and Nielsen (2015), and Lubotsky and Qureshi (2018). Here, instead, we study the timing of the transition from childcare to school.

Given that parents are constrained in terms of resources such as time, money and mental capacity, we expect a shock to one child's trajectory to affect the type, timing and amount of investments parents are able to make in other family members, including in their own relationship and careers. Parents have some flexibility in the allocation of money across various consumption and investment goods, which they can smooth over time by borrowing. They also have some leeway in the allocation of time between work, leisure and child investments, but the total available time is obviously fixed. Mental capacity is fully constrained in that there is limited opportunity to smooth resources over time. 
Studies that model multi-period resource allocation, such as Cunha and Heckman (2007), illustrate that in a dynamic process, constraints in one period lead to suboptimal investments in that period relative to other periods in life, possibly producing longlasting consequences. A very similar intuition applies to our setting: Because families are time-constrained, possibly even facing unanticipated stress due to, for instance, complications in children's critical transitions in the education system, they have limited actions available. Such critical transitions might therefore have consequences reaching beyond the child in question.

Our starting point is the observation that the critical transition from childcare to primary school puts additional pressure on parents' resource constraints. The existing literature has shown how a higher SSA has immediate consequences for a child's in-school performance and well-being (e.g. Bedard and Dhuey 2006; Dee and Sievertsen 2018); we posit that this could directly affect parents. One aspect of this concerns the extent and nature of parent-child interactions while at home. Figure 3A uses time use data to show parents' average daily time spent on childcare per parent during weekdays across child age. ${ }^{12}$ It is evident that both the time parents spend with their children (the solid line) and time spent reading to/with the child (the dotted line) decrease as children grow up, although with a local maximum around school start at ages 6-7. In line with this, as depicted in Figure 3B, parents report spending substantially more time doing home-work with children already enrolled in school (i.e. young-for-grade), with no visible differences in other activities.

Another aspect is simply time at home. Figure 3C depicts maternal employment patterns by age of the child. Full-time work increases with child age with a notable flattening out around school start. We see corresponding high rates of part-time work peaking during this period as well, only to decline afterwards. Figure 3D finally shows descriptively that children aged 7 already enrolled in first grade (i.e. young-for-grade) uniformly spend less 
time out-of-home than children not yet enrolled (i.e. old-for-grade). In Figure A2, we show that the difference in time out-of-home is largest for low-income mothers.

In conclusion, the figures illustrate that school start is associated with a change in parents' time-allocation, both in terms of activities while at home and in time at home. This is in accordance with, for example, findings from Pop-Eleches and Urquiola (2013) and Fredriksson, Öckert, and Oosterbeek (2016). Parents’ mental capacity (or stress level) is possibly also affected; Christensen (2004) reports that 34\% of parents state that their child's school start was particularly challenging due to psychological problems, issues related to concentration, language barriers, or conflicts with teachers or classmates. ${ }^{13}$

\section{$<$ FIGURE 3 APPROXIMATELY HERE>}

But not only may the parents be affected by the age at which one child starts school, siblings could too. Clearly, a change in the distribution of time use and the demands on mental resources may affect the investments that parents are able to make in their other children; for example, parents may either reinforce positive events (draw resources away from other siblings) or counteract and redistribute resources to other siblings. Analyses of the allocation of parental resources across children date back to the early work of Becker and Tomes (1976) and the topic remains high on the scientific agenda, as seen in the study by Yi et al. (2015), who study the reallocation of parental resources in a set-up with multiple skills in families with multiple children. Changes in parents' relationship stability and employment status may also directly affect siblings. More generally, because siblings interact, a change in one child's SSA (and, as a consequence, his outcomes) may introduce direct peer effects on other children. ${ }^{14}$ Relatedly, parents’ relationship stability may influence employment decisions and vice versa. Ultimately, the direction of the sum of the aforementioned effects on parent and sibling outcomes must be determined through empirical analysis. 
We expect effects of school start age on other family members to wear off with temporal distance to particularly sensitive or stressful periods in the lives of focal children, while keeping in mind that school start age shifts the timing of the entire education cycle. Hence it is certainly possibly that effects show up later too when new transitions materialize. We also conjecture that effects may vary with family background. For example, it is possible that constraints are more often binding if parents have other children or if their monetary or mental resources are limited. On the other hand, parents may learn from previous experience and consequences may be less in children with higher birth order.

\section{Methodology}

Our goal is to estimate the effect of SSA of child $i$ in family $f$ on outcomes of siblings and parents $j$ in the same family. Our equation of interest is the following:

$$
Y_{j f}=\alpha+\beta \cdot S S A_{i f}+X_{i f}^{\prime} \gamma+X_{j f}^{\prime} \delta+\varepsilon_{j f}
$$

where $Y$ denotes the outcome, $X$ observable characteristics and $\varepsilon$ unobservable characteristics. $^{15}$

In some sense, we can think about administrative SSA rules as affecting the incentives to enroll children later (or earlier) than prescribed by imposing time and effort costs on parents who do not comply with the regime. We can therefore instrument SSA with a dummy for being born immediately after January 1. As argued in the existing literature, such cutoff dates constitute valid instruments in the sense of being uncorrelated with unobserved characteristics of child outcomes. ${ }^{16,17}$ In order to estimate the local average treatment effect - the average effect of being old-for-grade for the group of children who would be inclined to increase their SSA solely because they were born in January as opposed to December — we also require that the monotonicity assumption is satisfied. Aliprantis (2012), Barua and Lang (2016), and Fiorini and Stevens (2013) argue, however, that 
monotonicity is likely to be violated if the school starting age distribution of children born just after the cutoff date does not stochastically dominate the corresponding distribution for children born just before the cutoff date. As explained in detail in Landersø, Nielsen, and Simonsen (2017), however, monotonicity is likely satisfied in our particular context. The intuition is that no children start more than one year before/after the date at which they are supposed to start (which would have introduced the possibility that some December children's school starting age could surpass the school starting age of January children, thus violating monotonicity), and SSA in our case is therefore effectively reduced to a binary variable indicating whether the child enrolls at age 6.6 or 7.6; see again Figure A1.

In practice, we consider a short bandwidth with focal children born \pm 30 days around January 1 . In our main specification, we model SSA as a binary variable indicating a SSA of 7.6 as opposed to 6.6. We show that conclusions are robust to extending the bandwidth around the cutoff. We also perform a variety of other standard sensitivity analyses that are all available upon request: a donut RD regression, models that exclude covariates and cohort fixed effects, and specifications with more flexible function in the running variable.

Finally, we perform a range of heterogeneity analyses to understand potential mechanisms. We investigate if the effects of SSA are more pronounced in connection with key stages such as school start itself but also graduation. Moreover, if the school starting age decision were viewed through the lens of a selection model, we should expect those who respond to the cutoff date instrument and change their child's SSA to be the families who would benefit from doing so. Thus, intuitively our results should be heterogeneous across both observable and unobservable characteristics. To investigate this, we perform heterogeneity analyses by gender, maternal education level, household income, and by birth order, and we also test whether we can rule out that our estimated effect can be generalized to non-compliers. 


\section{Data}

\section{A. Data Sources and Samples}

We exploit rich administrative Danish data containing information on all individuals residing in Denmark. Our data material provides the following crucial sets of information: 1) family outcomes and sibling school performance, 2) SSA and 3) rich background information. Registers are linked at the personal level via a unique personal identifier. Using parental identifiers, we are able to link children to their parents and siblings.

Our starting point is the set of children born from 1986 to 2000. Within this group, for the purposes of our formal analysis, we then select the focal child sample of individuals born around the January 1 cutoff. This sample consists of December-born children in the years 1986-1999 and January-born children from 1987-2000. The parent sample consists of the biological parents of focal children while the sibling sample is made up of siblings born to the same mothers as the focal children. Where two (or more) children from the same family are born around the January 1 cutoff in the observation period, there will be two (or more) focal children observed in the same family (7\% of all families in our parent sample are represented more than once because multiple children are born in December or January within our study period). ${ }^{18}$ Our sample initially includes both siblings who are younger and older than the focal children but our empirical analysis will consider older siblings, where the causal link to sibling outcomes is cleaner as older siblings have already started school and cannot be affected via changes to their own SSA. The Danish register data spans from 1980-2015, but grades are only available from 2002 and onwards. Therefore, we do not have a complete overlap between the samples used to study all outcomes for focal children, parents and siblings. 
Figure A3 shows the distribution of siblings by age spacing. The histogram illustrates the fraction of siblings for whom we have support for grades for older siblings. The closer siblings are spaced, the relatively more complete is the observation of outcomes in the sibling sample.

In order to ascertain that our results are not driven by skewness in spacing or calendar time in the estimation sample, we perform sensitivity analyses restricting the sample to cohorts where we have complete information about outcomes of all siblings within a maximum age distance of 3, 6 and 9 years, respectively. When we restrict the sample to a maximum of 3, 6 and 9 years age distance, we have complete information about the outcomes of older siblings for focal children born from 1990/91, 1993/94 and 1996/97, respectively, until 1999/2000.

\section{B. Key Variables and Descriptive Statistics}

\section{Measuring school starting age (SSA)}

We do not observe the exact timing of SSA for the cohorts under analysis. Instead, we use age in $8^{\text {th }}$ grade (minus eight) as an approximation. This works because the vast majority of old-for-grade children at the end of elementary school are already old-forgrade in Kindergarten, whereas very few children are delayed from grade 1 onwards. ${ }^{19}$

\section{Outcome variables}

We consider the effects of the focal child's SSA on a range of family outcomes: parents' relationship stability (measured by an indicator variable for whether parents are married/cohabiting measured on January 1 every year following school start), parental employment (measured by an indicator variable for whether parents are employed or not in November each year), and mothers' wage earnings from the income registers which are based 
on tax information. ${ }^{20}$ We also consider the impact on older siblings' academic performance in terms of exit exam results after grade 9.

Figure A4.A illustrates the proportion of parents cohabiting or married at a given focal child age. There is a steady flow out of marriage / cohabitation. When the focal child is 3 years old, around $85 \%$ of parents live together, while the number is down to $60 \%$ when the child turns 20. Figure A4.B shows the development in parental employment: Around $87 \%$ of fathers and $72 \%$ of mothers are employed when the child is 3 years old. As the focal child grows older, the maternal employment rate increases smoothly and approaches the paternal rate whereas fathers' employment rates are relatively stable across time. ${ }^{21}$

Similarly, Table $\mathrm{A} 1^{22}$ shows the distribution of older siblings' grades numerically and on the ECTS scale. In all tests the modal grade is C, and roughly one third score higher than $\mathrm{C}$ and one-third lower. In the empirical analysis, we standardize grades to have mean 0 and standard deviation 1 based on the numerical scale.

\section{Background characteristics}

Using the registers, we combine information on the children's birth weight, demographic variables and educational variables by the unique individual identification number. We also link these data to information about parents' characteristics as measured one year prior to and after the birth of the child. Descriptive statistics for the background characteristics and outcomes as measured before school start are reported in Table A2.

Importantly, we center all covariates and outcome variables on the cutoff dates instead of by calendar year. Hence, we compare background information on children born in January year t to the information on children born in December year $\mathrm{t}-1$ instead of comparing information on children born in January year t to the information on children born in December year t. ${ }^{23}$ Table 1 shows joint F-tests from a regression of the instrument on the rich 
set of background variables for children born \pm 30 days around January 1 . These tests clearly suggest that the sample is balanced across the cutoff. Also, columns 3 and 4 , where we include mothers' education and parents' characteristics as measured when their child is 5 years old, show that there is no response to children's timing of birth before their supposed school start. This picture is supported by the full set of regression results (reported in Table A3) and graphical evidence of balance on key covariates across the cutoff (illustrated in Figure A5). In the subsequent analyses the set of covariates consists of the variables included in column 2 of Table 1.

\section{$<$ TABLE 1 APPROXIMATELY HERE>}

Table A2 also shows the average characteristics of the compliers (those who are old-for-grade as a result of the administrative January 1 cutoff), estimated as described in e.g., Almond and Doyle (2011). The table illustrates how the average family size of compliers differs from the average family size of the remaining sample. Compliers are more likely to be girls and have more siblings. The latter indicates that the complier families in question may be particularly sensitive to shocks to time use and mental resources and more likely to be constrained in these aspects. There is a weak tendency for compliers to be positively selected in terms of other characteristics. ${ }^{24}$

\section{Results}

\section{A. Timing of Birth within the Calendar Year and School Starting Age}

Table 2 presents the results from the first stage regression using an indicator variable for birth in January as instrument for SSA. The table shows the first stage results estimated both with and without background variables. Note that the coefficient estimate associated with the instrument does not change with the inclusion of other control variables. All specifications include cohort fixed effects (indicator variables for being born Dec 1986- 
Jan 1987, Dec 1987-Jan 1988 etc.) and the distance in days to the cutoff linearly. Being born in January rather than December increases the likelihood of child school start at age 7.6 instead of at 6.6 years with 20 percentage points. The associated F-statistic for the version that conditions on observable characteristics is almost 2,400 and thus well above the standard Staiger and Stock (1997) rule-of-thumb of $10 .^{25}$

$<$ TABLE 2 APPROXIMATELY HERE $>$

\section{B. Effects on Parents}

This section investigates parents' own responses to the timing of their child's school start. For each outcome we present three sets of results. First, we show the usual 2SLS estimates across children's age. Second, to accompany and deepen our understanding of the 2SLS results, we estimate compliers' potential outcomes if children were young-for-grade or old-for-grade, in line with Abadie (2002, 2003). If, on the one hand, the potential outcomes diverge exactly around the critical stages but are aligned otherwise, effects likely arise due to an easier transition between different educational stages. If, on the other hand, potential outcomes are parallel across ages, this supports a hypothesis that effects stem from a simple intertemporal response to the postponement of the child's life-course including all critical transitions by one year. Lastly, we combine the 2SLS analysis with a re-estimation of the effects of being old-for-grade on parents' relationship status and maternal employment rates where we align the outcomes by grade level instead of age. If results arise from parallel changes to parents' trajectories as a consequence of the delayed life-course, the estimated effects for outcomes centered by grade level should be miniscule, whereas if our findings arise because postponing children's SSA actually eases the transition, effects should persist around the timing of the transitions, even when we center outcomes by grade level. ${ }^{26}$ 
Figure 4A shows the estimated effects of being old-for-grade on the probability that parents live together (married or cohabiting) at a given age. Until age 6, the point estimates are small and not significantly different from zero. In some sense, we can think of this as a placebo test (or a test of foresight) as children have yet to start school. From the child turns 7 and onwards, the family is more likely intact if the focal child is old-for-grade than young-for-grade, although the estimates are only borderline significant at a $10 \%$ level. The old-for-grade children are in kindergarten at this exact January 1 cutoff, whereas youngfor-grade children are in grade 1 . The coefficient estimates jump again around the focal child's $15^{\text {th }}$ birthday. At this point in time, children who are old-for-grade are in the middle of $8^{\text {th }}$ grade while the young-for-grade children are in the middle of grade 9 and approach the lower secondary exit exam taking place 6 months later in June. ${ }^{27}$ The significant effects of being old-for-grade on parents' relationship status are, however, not persistent in the longer run. They peak when the child is aged 15-17 and approach zero afterwards. Thus, when the child reaches adulthood there are fewer separations, and age at school start no longer influences whether parents live together.

Figure 4B presents the counterfactual outcomes in the old-for-grade and youngfor-grade states of those who are old-for-grade if they were born on January $1^{\text {st }}$ and not on December $31^{\text {st }}$. The vertical distance between the two lines correspond to the estimates plotted in Figure 4A. Figure 4B shows a smooth reduction in parental marital/cohabitation rates if the child is young-for-grade $\left(\mathrm{Y}_{0}\right)$. If the child is old-for-grade $\left(\mathrm{Y}_{1}\right)$, parents would follow the same trajectory until school start, where parental marital/cohabitation rates stagnate for one year. From age 7 until 14, parents' marital/cohabitation rates follow parallel trends, regardless of SSA. At age 14, marital/cohabitation rates of old-for-grade parents stagnate, while they decline for young-for-grade parents. This is followed by a gradual convergence between the two counterfactual outcomes until the child is 21 years old. 
Consequently, in Figure 4C, the estimated effects from daycare until grade 8, when we align parents' relationship status by grade level, are insignificant and close to zero, suggesting that any initial response on parents' relationship stability is a result of the focal child's postponed life-course. From grades 10-12, however, significant effects of being old-for-grade on the parents' marital/cohabitation rates emerge. These are exactly the years when the child finishes compulsory schooling and enrolls in upper secondary school, suggesting that the transitions into primary school and later into upper secondary school do not impact family resources similarly.

\section{$<$ FIGURE 4 APPROXIMATELY HERE $>$}

Figure 5A shows the estimated effects of a child's SSA on maternal employment by child age. Mothers work more often when the focal child is age 7 if school start is later. At age 7, young-for-grade children have started first grade while old-for-grade children are still in Kindergarten. Note that there are no significant effects on employment before age seven. Estimates are still positive once both young- and old-for-grade children have started school (age eight and onwards) but become statistically insignificant. ${ }^{28}$ Figure A6.B shows the corresponding reduced form at child age 7. Together, these results suggest that maternal labor supply is hindered by constraints within the family; constraints, which are removed in the short run by postponing school start. ${ }^{29}$

Around $75 \%$ of mothers are already working when the child is aged 7, and therefore a natural next question is what type of mothers drive the effects. We explore this in our analyses in Sections V.C and V.D. We find no effects of a child's SSA on paternal employment (not shown) as paternal employment rates are high and stable across focal child age (see Figure A4.B).

When we focus on how the counterfactual employment rates diverge at age 7 , Figure 5B shows employment rates for mothers who have old-for-grade children are 
consistently above those for mothers who have young-for-grade children until the child turns 17, the largest differences being in the early schooling years. Hence, a later school start allows parents to allocate more resources to themselves and parents (mothers) respond to the decision of delayed school start immediately after the decision has been put into effect. This is confirmed by Figure 5C, which shows that being old- for-grade results in significant, positive effects. During grades 1-3, maternal employment rates increase by 4-6 percentage points (5-7\% relative to $\mathrm{Y}_{0}$ ) if their child is old-for-grade. ${ }^{30}$

To recapitulate we note two striking aspects of parental responses to school starting age. First of all, the positive effects on maternal employment are closely aligned with the uptick in parental relationship stability. This is consistent with the hypothesis that both are driven by SSA (or that they are complementary responses) but not with the hypothesis that maternal employment leads to family disruption. Second, the effects are sizeable. Therefore, it is appropriate to emphasize the local nature of the effects. In a standard selection model, compliers are selected on gains, and the magnitude is large because we estimate the effects for the group who are the ones who benefit from postponing children’s SSA. We substantiate this explanation in Section V.F.

<FIGURE 5 APROXIMATELY HERE>

\section{Margins of Response}

As the employment variable used above only measures extensive margin responses, the results on mothers’ labor supply beg two new questions: Are there underlying intensive margin adjustments for mothers who already hold a job, and do mothers take up part-time or full-time jobs? As a first step, Figure A9.A shows the effects of being old-forgrade on mother's place in the earnings distribution of all mothers in Denmark by focal child's age. The figure mimics the findings from Figure 5A and show a borderline significant 
effect around school start at ages 7-9 with average income percentiles increasing by 2-3 percentage points if the child is old-for-grade instead of young-for-grade. Furthermore, Figure A9.B illustrates the margin of response: mothers are more likely to move away from the bottom quartile of earnings if their child is old-for-grade.

In Figure 6 we investigate these effects in greater detail by showing how being old-for-grade affects the earnings distribution of mothers in our sample at ages 7, 8, and 9. To do so we create a series of indicator variables for whether a given individual's wage earnings fall below a given level. We then vary the cutoff level from 0 to the maximum observed earnings in our sample and estimate separate regressions using each of the indicator variables as outcomes. The estimated effects of being old-for-grade will thereby show how the cumulated earnings distribution is affected by the child's SSA. Figures $6 \mathrm{~A}, \mathrm{C}$, and E show the counterfactual cumulated earnings distributions for compliers at age 7, 8, and 9. Figures 6B, $\mathrm{D}$, and $\mathrm{F}$ show the corresponding 2SLS estimates of the effects of being old-for-grade on the cumulative distribution of mothers' earnings, which corresponds to the vertical distance between the lines in Figures A, C, and E. Extensive margin effects will be the vertical differences between the lines and the corresponding 2SLS estimates at \$0. Intensive margin effects implies mass being shifted upwards in the earnings distributions at positive levels of earnings. This will be manifested as ranges where the vertical distances between the lines in Figures A, C, and E grow and the point estimates in Figures B, D, and F decrease (increase numerically).

From Figure 6 we see that a substantial change has taken place at the extensive margin. As found in Figure 5, extensive margin effects at ages 7 and 8 are on average roughly 4-5 percentage points and only 2 percentage points at age 9 . Figure 6 , however, also shows substantial underlying intensive margin effects. There are around 5\% fewer mothers earning below $\$ 20,000$ per year (which corresponds to part-time work), even at age 9 which showed 
no statistically significant extensive margin effect. From the figure we see that these mothers have been shifted from wage earnings in the range between $\$ 1-20,000$ to wage earnings between \$20-40,000 which are the ranges where the solid and dashed lines in Figures A, C, and $\mathrm{E}$ converge and the point estimates in $\mathrm{B}, \mathrm{D}$, and $\mathrm{E}$ moves towards zero. ${ }^{31}$

<FIGURE 6 APPROXIMATELY HERE>

\section{Heterogeneity by Parental Background Characteristics}

We next investigate the degree to which our findings differ with parental education. We first break the employment rates of mothers down by education and child's age in Figure A10. The figure shows that low educated mothers' labor supply increases gradually as the child grows older partly due to extensive margin movements (from no employment to employment) and partly due to intensive margin transitions (from part-time to full-time employment). However, highly educated mothers have a flat employment rate at a high level (88\%) - even before the child enters school - and they only adjust at the intensive margin with switches from part-time to full-time. While our findings in Figure 6 indicate both extensive and intensive margin effects for the total sample, we expect the extensive margin responses to be concentrated among low educated mothers. This is confirmed in Figure A11 where we show effects of being old-for-grade on parents' relationship status and maternal employment (as measured by an indicator variable thus capturing the extensive margin adjustments) by mothers’ education. ${ }^{32}$

In Figure A12, we break the employment effects down by job type. The figures show that the positive employment effects for low educated mothers are driven by increased employment in care (welfare sector), sales or services work. Furthermore, the figures show that there are no job type adjustments conditional on employment. This underscores our 
earlier interpretation of intensive margin effects arising from adjustments of hours worked at a given job type and not better paid jobs for a given level of labor supply.

Together, the results presented in Sections V.B-V.D not only illustrate that a substantial fraction of mothers increase labor supply and enter employment as a result of families being relieved of time and mental constraints when a child's school start is postponed, but also that this benefits mothers who already hold a job and can increase labor supply at the intensive margin and move from part-time to full-time employment.

\section{E. Further Evidence of Resource Constraints: Effects on Siblings}

Other indicators of binding resource constraints are related to other offspring in the family as indicated by family size, birth orders, fertility, and sibling outcomes. Responses to stressful experiences with one child may depend on the overall family size or the presence of younger or older children in the family, which is illustrated by our earlier finding that compliers’ family sizes are larger than the sample average (Table A2). Figure A13 shows that children who are not first-born or only children drive our main results. ${ }^{33}$ This suggests that parents do not adjust the timing of split-up or the extent of employment when faced with first-borns' or only children's struggles with transitions in the education system, but they do so for younger siblings. This indicates that parents take into account the dynamics of the entire family and aligns behavior with the education cycle of younger offspring, or that the time-constraints are mainly binding during younger siblings’ school start and not for example during the school start of only children.

\section{<TABLE 3 APPROXIMATLYER HERE $>$}

Now we formally investigate consequences of stress due to parental resource constraints around the focal child's transitions in the education system. In Table 3, we present the estimation results for the effects of the focal child's SSA on grades of older siblings. ${ }^{34}$ 
The results confirm the pattern seen above: that a higher SSA seems to ease school experience and release resources in the family. A higher SSA of the focal child does not significantly affect the grades of older siblings who are in lower or middle primary school at the time of the focal child's supposed school start. Yet for siblings who are 7-9 years older than the focal child, a higher SSA improves grades substantially. ${ }^{35}$ Note, though, that estimated effects are imprecise and we suggest caution in interpreting the magnitude. These older siblings receive their first teacher assessments and approach graduation at the time when the focal child transitions into elementary school. ${ }^{36}$ An easier school start of the focal child likely improves the performance of the older siblings because the study environment at home is better or because parental resources are freed to assist with homework. In support of this interpretation, only grades in written math and Danish grammar are significantly improved as opposed to grades in essay writing or the oral examination of text analysis. The former disciplines require lower levels of cognition (knowledge, comprehension and application), whereas the latter disciplines require higher levels of cognition (analysis, synthesis, evaluation). ${ }^{37}$ Thus, the former disciplines are more closely related to rote learning and thereby easier to practice, while the latter require verbal creativity and ideational fluency, which are not readily improved in the short run. Interestingly, as shown in Table A7, we see that it is particularly the lower and mid-range grades that are affected by sibling SSA. The probability of receiving at least a $\mathrm{B}, \mathrm{C}$ or $\mathrm{D}$ in written math and Danish grammar increases with sibling SSA, while the effect of SSA on receiving an A is close to zero and the probability of receiving an E or F becomes less likely. Hence, the effects on siblings' grades are indeed concentrated in margins where the road to improved test scores is relatively straightforward.

The effects of SSA on sibling outcomes may also partly run through marital stability or through household income, both of which have been shown to affect children's 
outcomes (Piketty 2003; Gruber 2004; Dahl and Lochner 2012). If this were the case, we might have expected larger effects of SSA on sibling outcomes for children of low educated mothers, because effects on parental outcomes to a high extent are driven by this subgroup (recall Figure A11). Yet, when we investigate effects on siblings' grades by maternal education we find no statistical or qualitative heterogeneity in effects on siblings' grades. ${ }^{38}$

To sum up, we interpret our results as suggesting that effects of being old-forgrade on siblings are not caused by effects on parents' outcomes but rather from the relief of constraints within the families. All families seem to be constrained in terms of investing in their children, while parents with low education face additional constraints in terms of their own outcomes (labor supply and marital stability).

\section{F. Selection on Unobserved Variables and External Validity}

The high rate of non-compliance seen already in Figure 1 hinted that selective compliance prevails. We now investigate selection on unobserved variables more formally and, within that context, discuss the external validity of our results. We have so far interpreted the results as effects for specific time-constrained families whose choice of SSA is affected by the institutions and policy-environment they face. If this were indeed the case, we would expect our estimated effects of school start age to be local and not generalizable to other types of families who are not constrained in a similar manner.

To test this, we therefore employ the two tests of the conditional independence assumption suggested by Black et al. (2015). We test expected outcomes for never-takers $\left(\mathrm{E}\left(\mathrm{Y}_{0} \mid \mathrm{SSA}_{1}=0, \mathrm{SSA}_{0}=0\right)\right)$ and always-takers $\left(\mathrm{E}\left(\mathrm{Y}_{1} \mid \mathrm{SSA}_{1}=1, \mathrm{SSA}_{0}=1\right)\right)$ against the outcomes for compliers and compute "biases,” $\mathrm{B}_{0}$ and $\mathrm{B}_{1}$. These measure the difference in expected outcome of never-takers compared to compliers conditional on being young-for- 
grade $\left(\mathrm{B}_{0}\right)$, and the difference in the expected outcome of compliers compared to alwaystakers conditional on being old-for-grade $\left(\mathrm{B}_{1}\right)$.

Figure $\mathrm{A} 14$ shows $\mathrm{B}_{0}$ and $\mathrm{B}_{1}$ using parents’ marriage/cohabitation rates as outcome. The figure reveals that the relationship stability of compliers' parents is higher because they are favorably selected compared to always-takers (even borderline significant before school start), whereas there are no differences between non-treated compliers and never-takers. At ages 15-19, in particular, marriage/cohabitation rates of parents to old-forgrade compliers are substantially higher relative to the parents of always-takers, suggesting that the parental response during the years around graduation from compulsory education is a consequence only for certain types of families.

Likewise, Figure $\mathrm{A} 15$ shows $\mathrm{B}_{0}$ and $\mathrm{B}_{1}$ for maternal employment rates. The figure shows that there are not any significant pre-school differences in maternal employment rates, while differences emerge later in the children's life. These differences are statistically significant for always-takers from ages 7-15, while they are rarely significant for nevertakers.

In conclusion, Figures A14 and A15 emphasize that the expected outcomes conditional on treatment status for compliers tend to be equal to that observed for nevertakers, but not for always-takers. This is because the main component in the school start decision is child maturity, school readiness and behavior in childcare. Among always-taking families, these factors dictate SSA no matter whether the child is born on one or the other side of the cutoff. It is thus reassuring that our analyses show that the family responses to later school start are present for particular types of families, and not readily extrapolated to the population as a whole.

\section{Conclusion}


This paper explores intra-family spillovers from the timing of an important life event, namely the age at which one child in the family starts school. Because the age at school start affects the entire life course, it also naturally impacts the timing of other important educational transitions. Our research design exploits quasi-random shifts in the timing of transitions into (and effectively also away from) school induced by date of birth around an administrative cutoff date.

Our findings reveal that SSA is important for family outcomes for both parents and siblings. Parents are more likely to remain together during their child's childhood and adolescence and mothers are more likely to increase their labor supply at both the extensive and intensive margins at the time of school start if the child starts grade 1 at age 7.6 rather than 6.6. It is perhaps not surprising that families make adjustments in transition years but to the best of our knowledge, this has not been documented previously, while at the same time substantial research effort has been spent in understanding causes of divorce and parental employment as well as their impact on children.

Older siblings improve their academic achievement if the focal child is older when they enroll in school. Hence, the key to understanding the increasing average age of school start seen around the Western world may not only lie in the individual children but also in the constraints and challenges that families experience today, Therefore, in designing policies directed at children, it is important to recognize that educational institutions and decisions affect not only the children in question, but also a wider set of agents as the policies may generate substantial spillover effects and influence important decisions made within families.

\section{References}


Abadie, Alberto. 2002. "Bootstrap Tests for Distributional Treatment Effects in Instrumental Variable Models.” Journal of the American Statistical Association 97(457): 284-292.

Abadie, Alberto. 2003. "Semiparametric instrumental variable estimation of treatment response models.” Journal of Econometrics 113(2): 231-263.

Aliprantis, Dionissi. 2012. "Redshirting, compulsory schooling laws, and educational attainment.” Journal of Educational and Behavioral Statistics 37(2): 316-38.

Almlund, Mathilde, Angela Lee Duckworth, James J. Heckman, and Tim D. Kautz. 2011. "Personality Psychology and Economics.” Chapter 1 in the Handbook of the Economics of Education 4: 1-181, Elsevier.

Almond, Douglas, and Joseph J. Doyle. 2011. ”After Midnight: A Regression Discontinuity Design in Length of Postpartum Hospital Stays.” American Economic Journal: Economic Policy 3(3): 1-34.

Andersen, Signe Hald, and Christopher Wildeman. 2014. “The Effect of Paternal Incarceration on Children’s Risk of Foster Care Placement.” Social Forces 93(1): 269-298.

Barua, Rashmi, and Kevin Lang. 2016. “School Entry, Educational Attainment and Quarter of Birth: A Cautionary Tale of a Local Average Treatment Effect.” Journal of Human Capital 10(3): 347-376.

Becker, Gary S., and Nigel Tomes. 1976. “Child Endowments and the Quantity and Quality of Children.” Journal of Political Economy 84(4): S143-S162.

Becker, Gary S., and Nigel Tomes. 1979. “An equilibrium theory of the distribution of income and intergenerational mobility.” Journal of Political Economy 87: 1153-1189. 
Bedard, Kelly, and Elizabeth Dhuey. 2006. “The persistence of early childhood maturity: international evidence of long-run age effects.” Quarterly Journal of Economics 121(4): 1437-1472.

Black, Dan A., Joonhwi Joo, Robert LaLonde, Jeffrey A. Smith, and Evan J. Taylor. 2015. “Simple Tests for Selection Bias: Learning More from Instrumental Variables”’ IZA DP \#9346.

Black, Sandra E., Sanni N. Breining, David Figlio, Jonathan Guryan, Krzysztof Karbownik, Helena Skyt Nielsen, Jeffrey Roth, and Marianne Simonsen. 2017. “Sibling Spillovers.” NBER WP \#23062.

Black, Sandra E., Paul J. Devereux, and Kjell G. Salvanes. 2011. “Too young to leave the nest? The effects of school starting age.” Review of Economics and Statistics 93(2): 455-467.

Blau, Francine D., and Lawrence M. Kahn. 2017. “The Gender Wage Gap: Extent, Trends, and Explanations.” Journal of Economic Literature 55(3): 789-865.

Bloom, Benjamin. 1956. Taxonomy of educational objectives: The classification of educational goals. England: Longman Group.

Bonke, Jens, and Peter Fallesen. 2010. “The impact of incentives and interview methods on response quantity and quality in diary- and booklet-based surveys.” Survey Research Methods 4(2): 91-101.

Breining, Sanni Nørgaard. 2014. “The presence of ADHD: Spillovers between siblings.” Economics Letters 124(3): 469-473.

Buckles, Kasey S., and Daniel M. Hungerman. 2013. "Season of Birth and Later Outcomes: Old Questions, New Answers.” Review of Economics and Statistics 95(3): 711-724. 
Cascio, Elizabeth, Steven J. Haider, and Helena Skyt Nielsen. 2015. “The effectiveness of policies that promote labor force participation of women with children: A collection of national studies.” Labour Economics 36 (October): 64-71.

Cascio, Elizabeth, and Diane Whitmore Schanzenbach. 2013. “The Impacts of Expanding Access to High-Quality Preschool Education.” Brookings Papers on Economic Activity, Economic Studies Program 47(2): 127-192.

Christensen, Else. 2004. 7 years childhood: Welfare, health and well-being in children born 1995. (In Danish: 7 års børneliv: Velfærd, sundhed og trivsel hos børn født i 1995). Report from the Danish National Centre for Social Research (SFI).

Cook, Philip J., and Songman Kang. 2016. “Birthdays, Schooling, and Crime: Regression-Discontinuity Analysis of School Performance, Delinquency, Dropout, and Crime Initiation.” American Economic Journal: Applied Economics 8(1): 33-57.

Cunha, Flavio, and James J. Heckman. 2007. “The technology of skill formation.” American Economic Review 97(2): 31-47.

Dahl, Gordon, and Lance Lochner. 2012. “The Impact of Family Income of Child Achievement: Evidence from the Earned Income Tax Credit.” American Economic Review 102(5): 1927-1956.

Datta Gupta, Nabanita, and Marianne Simonsen. 2010. “Non-cognitive Child Outcomes and Universal Child Care.” Journal of Public Economics 94 (1-2): 30-43.

Dee, Thomas, and Hans Henrik Sievertsen 2018. “The Gift of Time? School Starting Age and Mental Health.” Health Economics 27(5): 781-802.

Deming, David, and Susan Dynarski. 2008. "The Lengthening of Childhood.” Journal of Economic Perspectives 22(3): 71-92.

Dhuey, Elizabeth, David Figlio, Krzysztof Karbownik, and Jeffrey Roth. 2017. “School Starting Age and Cognitive Development.” NBER WP \# 23660. 
Dustmann, Christian, Patrick Puhani, and Uta Schönberg. 2017. “The LongTerm Effects of Early Track Choice.” Economic Journal 127(603): 1348-1380.

Elder, Todd E. 2010. “The importance of relative standards in ADHD diagnoses: evidence based on exact birth dates.” Journal of Health Economics 29(5): 641656.

Evans, William N., Melinda S. Morrill, and Stephen T. Parente. 2010. "Measuring excess medical diagnosis and treatment in survey data: the case of ADHD among school-age children.” Journal of Health Economics 29(5): 657-673.

Fiorini, Mario, and Katrien Stevens. 2013. “Assessing the Monotonicity Assumption in IV and fuzzy RD designs.” Working Paper 2013-06, University of Sydney. Fitzpatrick, Maria D. 2012. “Revising Our Thinking about the Relationship between Maternal Labor Supply and Preschool.” Journal of Human Resources 47(3): 583612.

Fredriksson, Peter, and Björn Öckert. 2013. "Life-cycle effects of age at school start.” Economic Journal 124(579): 977-1004.

Fredriksson, Peter, Björn Öckert, and Hessel Oosterbeek. 2016. “Parental Responses to Public Investments in Children: Evidence from a Maximum Class Size Rule.” Journal of Human Resources 51(4): 832-868.

Garces, Eliana, Duncan Thomas, and Janet Currie. 2002. “Longer-Term Effects of Head Start.” American Economic Review 92(2): 999-1072.

Gelbach, Jonah B. 2002. “Public Schooling for Young Children and Maternal Labor Supply.” American Economic Review 92(1): 307-322.

Gelber, Alexander, and Adam Isen. 2013. “Children’s Schooling and Parents’ Behavior: Evidence from the Head Start Impact Study.” Journal of Public Economics 101(May): 25-38. 
Gruber, Jonathan. 2004. “Is Making Divorce Easier Bad for Children? The Long-Run Implications of Unilaterial Divorce.” Journal of Labor Economics 22(4): 799-833.

Havnes, Terjei, and Magne Mogstad. 2011. “Money for nothing? Universal child care and maternal employment.” Journal of Public Economics 95 (11-12): 1455-1465.

Holmes, Thomas H., and Richard H. Rahe. 1967. "The social readjustment rating scale.” Journal of Psychosomatic Research 11(2): 213-218.

Joensen, Juanna Schrøter, and Helena Skyt Nielsen. 2018. “Spillovers in Education Choice.” Journal of Public Economics 157(January): 158-183.

Kvist, Anette Primdal, Helena Skyt Nielsen, and Marianne Simonsen. 2013. “The Importance of Children’s ADHD for Parents’ Relationship Stability and Labor Supply.” Social Science and Medicine 88(July): 30-38.

Kuziemko, Iliana. 2014. “Human Capital Spillovers in Families: Do Parents Learn from or Lean on Their Children?” Journal of Labor Economics 32(4): 755-786.

Landersø, Rasmus Kløve, Helena Skyt Nielsen, and Marianne Simonsen. 2017. “School Starting Age and the Crime-Age Profile.” Economic Journal 127(602): 1096-1118. Lubotsky, Darren, and Javaeria Qureshi. 2018. “Assessing the Smooth Rise in Mothers' Employment as Children Age.” Journal of Human Capital 12(4): 604-639.

Manski, Charles F. 1993. "Identification of endogenous social effects: The reflection problem.” Review of Economic Studies 60(3): 531-542.

Nicoletti, Cheti, and Brigitta Rabe. 2016. ”Sibling spillover effects on school achievements.” Discussion Papers in Economics 16/02, University of York.

Piketty, Thomas. 2003. “The Impact of Divorce on School Performance: Evidence from France, 1968-2002.” CEPR Discussion Paper no. 4146, London.

Pop-Eleches, Cristian, and Miguel Urquiola. 2013. “Going to a Better School: Effects and Behavioral Responses.” American Economic Review 103(4): 1289-1324 
Qureshi, Javaeria. 2018. “Siblings, Teachers and Spillovers on Academic Achievement” Journal of Human Resources 53(1): 272-297.

Qureshi, Javaeria. Forthcoming. 'Additional Returns to Investing in Girls' Education: Impact on Younger Sibling Human Capital?’ Forthcoming in Economic Journal. Skolestartsudvalget (2006), A good school start. A cohesive education including preschool, school and after-school care. (In Danish: En god skolestart. Et samlet læringsforløb for dagtilbud, indskoling og fritidsordning). Report from the Government’s Committee on School Start, Feb 2006.

Staiger, Douglas, and James H. Stock. 1997. “Instrumental Variables Regression with Weak Instruments.” Econometrica 65(3): 557-586.

Yi, Junjian, James J. Heckman, Junsen Zhang, and Gabriella Conti. 2015. “Early Health Shocks, Intra-Household Resource Allocation and Child Outcomes.” Economic Journal 125(588): F347-F371.

Young, Alwyn. 2017. “Consistency without Inference: Instrumental Variables in Practical Application.” Manuscript, London School of Economics. 
TABLES AND FIGURES

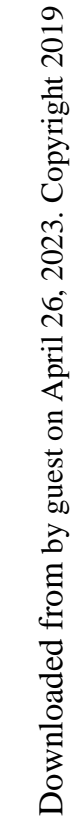


Table 1

Balancing Test

\begin{tabular}{lcccc}
\hline & $(1)$ & $(2)$ & $(3)$ & $(4)$ \\
\hline F-statistic & 1.00 & 0.84 & 0.90 & 0.78 \\
p-value & 0.43 & 0.55 & 0.50 & 0.60 \\
\hline Observations & 132,039 & 132,039 & 132,039 & 132,039 \\
\hline Distance to cutoff & $\mathrm{X}$ & $\mathrm{X}$ & $\mathrm{X}$ & $\mathrm{X}$ \\
Child characteristics at birth & $\mathrm{X}$ & $\mathrm{X}$ & $\mathrm{X}$ & $\mathrm{X}$ \\
Parental characteristics, child age 3 & $\mathrm{X}$ & $\mathrm{X}$ & $\mathrm{X}$ & $\mathrm{X}$ \\
Cohort fixed effects & & $\mathrm{X}$ & & $\mathrm{X}$ \\
Additional parental characteristics, child age 5 & & & $\mathrm{X}$ & $\mathrm{X}$ \\
\hline
\end{tabular}

Note: Table shows F-statistics and associated p-values from OLS regressions. Columns 1 and

2 show results of a regression of birth month (January $=1$ ) on distance to cutoff (in days), background characteristics of focal child and parents and cohort fixed effects, whereas columns 3 and 4 show results when additional parental characteristics at age 5 are added (marriage /cohabitation and maternal employment). Full set of estimation results are presented in Table A3. 
Table 2

First Stage Results

\begin{tabular}{lcc}
\hline & $(1)$ & $(2)$ \\
\hline January (0/1) & $0.201^{* * *}$ & $0.201^{* * *}$ \\
Distance to cutoff, January & $(0.005)$ & $(0.004)$ \\
& $0.002^{* * *}$ & $0.002^{* * *}$ \\
Distance to cutoff, December & $(0.000)$ & $(0.000)$ \\
& $-0.004^{* * *}$ & $-0.004^{* * *}$ \\
Birth weight<2000g & $(0.000)$ & $(0.000)$ \\
& & $0.157^{* * *}$ \\
Boy & & $(0.015)$ \\
& & $0.178^{* * *}$ \\
Boy*Birthweight<2000g & & $(0.002)$ \\
& & $-0.079^{* * *}$ \\
\# Older siblings & & $(0.021)$ \\
& & $-0.012^{* * *}$ \\
Parents married/cohab. year before birth & & $(0.003)$ \\
& & -0.005 \\
Mother's age at birth & & $(0.003)$ \\
Father's age at birth & & -0.000 \\
Constant & & $(0.000)$ \\
& & $-0.002^{* * *}$ \\
Observations & & $(0.000)$ \\
R squared & & $0.627^{* * *}$ \\
F-statistics & & $(0.008)$ \\
\hline
\end{tabular}

Note: Table shows results from linear regressions of indicators for starting school at age 7.6 instead of 6.6 for children born in December or January while conditioning on the cutoff dummy (January = 1), distance to cutoff, cohort fixed effects and background characteristics. Standard errors in parentheses $+\mathrm{p}<0.10,{ }^{*} \mathrm{p}<0.05,{ }^{* *} \mathrm{p}<0.01,{ }^{* * *} \mathrm{p}<0.001$. 
Table 3

Effects of Being Old-for-Grade on Older Siblings' Grades by Distance in Focal Child's and Sibling's Age

\begin{tabular}{|c|c|c|c|c|}
\hline Age difference & OLS & 2SLS & 2SLS & Observations \\
\hline \multicolumn{5}{|c|}{ Math, standard deviations } \\
\hline $1-3$ years & $\begin{array}{l}-0.107 * * * \\
(0.012)\end{array}$ & $\begin{array}{l}0.122 \\
(0.104)\end{array}$ & $\begin{array}{l}0.056 \\
(0.100)\end{array}$ & 31,505 \\
\hline 4-6 years & $\begin{array}{l}-0.128^{* * *} \\
(0.019)\end{array}$ & $\begin{array}{l}-0.032 \\
(0.183)\end{array}$ & $\begin{array}{l}-0.115 \\
(0.174)\end{array}$ & 14,024 \\
\hline $7-9$ years & $\begin{array}{l}-0.132 * * * \\
(0.034)\end{array}$ & $\begin{array}{l}1.065 * * \\
(0.392)\end{array}$ & $\begin{array}{l}0.985 * * \\
(0.355)\end{array}$ & 4,557 \\
\hline \multicolumn{5}{|c|}{ Danish essay, standard deviations } \\
\hline $1-3$ years & $\begin{array}{l}-0.066 * * * \\
(0.012)\end{array}$ & $\begin{array}{l}0.134 \\
(0.104)\end{array}$ & $\begin{array}{l}0.116 \\
(0.098)\end{array}$ & 31,505 \\
\hline 4-6 years & $\begin{array}{l}-0.079 * * * \\
(0.018)\end{array}$ & $\begin{array}{l}0.096 \\
(0.182)\end{array}$ & $\begin{array}{l}0.003 \\
(0.171)\end{array}$ & 14,024 \\
\hline $7-9$ years & $\begin{array}{l}-0.119 * * * \\
(0.033)\end{array}$ & $\begin{array}{l}0.037 \\
(0.345)\end{array}$ & $\begin{array}{l}0.101 \\
(0.311)\end{array}$ & 4,557 \\
\hline \multicolumn{5}{|c|}{ Danish grammar, standard deviations } \\
\hline $1-3$ years & $\begin{array}{l}-0.102^{* * *} \\
(0.012)\end{array}$ & $\begin{array}{l}0.106 \\
(0.103)\end{array}$ & $\begin{array}{l}0.079 \\
(0.099)\end{array}$ & 31,505 \\
\hline 4-6 years & $\begin{array}{l}-0.121^{* * *} \\
(0.018)\end{array}$ & $\begin{array}{l}0.279 \\
(0.184)\end{array}$ & $\begin{array}{l}0.189 \\
(0.175)\end{array}$ & 14,024 \\
\hline $7-9$ years & $\begin{array}{l}-0.139 * * * \\
(0.033)\end{array}$ & $\begin{array}{l}0.768 * \\
(0.368)\end{array}$ & $\begin{array}{l}0.763 * \\
(0.336)\end{array}$ & 4,557 \\
\hline \multicolumn{5}{|c|}{ Danish oral, standard deviations } \\
\hline $1-3$ years & $\begin{array}{l}-0.081^{* * *} \\
(0.012)\end{array}$ & $\begin{array}{l}0.097 \\
(0.103)\end{array}$ & $\begin{array}{l}0.076 \\
(0.099)\end{array}$ & 31,505 \\
\hline 4-6 years & $\begin{array}{l}-0.101^{* * *} \\
(0.019)\end{array}$ & $\begin{array}{l}-0.043 \\
(0.182)\end{array}$ & $\begin{array}{l}-0.123 \\
(0.174)\end{array}$ & 14,024 \\
\hline 7-9 years & $\begin{array}{l}-0.105^{* *} \\
(0.034)\end{array}$ & $\begin{array}{l}-0.124 \\
(0.342)\end{array}$ & $\begin{array}{l}-0.070 \\
(0.316) \\
\end{array}$ & 4,557 \\
\hline $\begin{array}{l}\text { Distance to cutoff } \\
\text { Covariates }\end{array}$ & $\begin{array}{l}\mathrm{X} \\
\mathrm{X}\end{array}$ & $\mathrm{X}$ & $\begin{array}{l}\mathrm{X} \\
\mathrm{X}\end{array}$ & \\
\hline
\end{tabular}

Note: Table shows the estimated effects of being old-for-grade based on OLS and 2SLS regressions of older siblings' grades at the end of grade 9. Each table cell represents an estimate for one specific subgroup defined by age distance between siblings. Cutoff dummy (January $=1$ ) used as instrument. Conditioning set includes distance to cutoff, cohort fixed effects and background characteristics (see Table 2). Standard errors in parentheses $+\mathrm{p}<$ $0.10,{ }^{*} \mathrm{p}<0.05,{ }^{* *} \mathrm{p}<0.01, * * * \mathrm{p}<0.001$ 


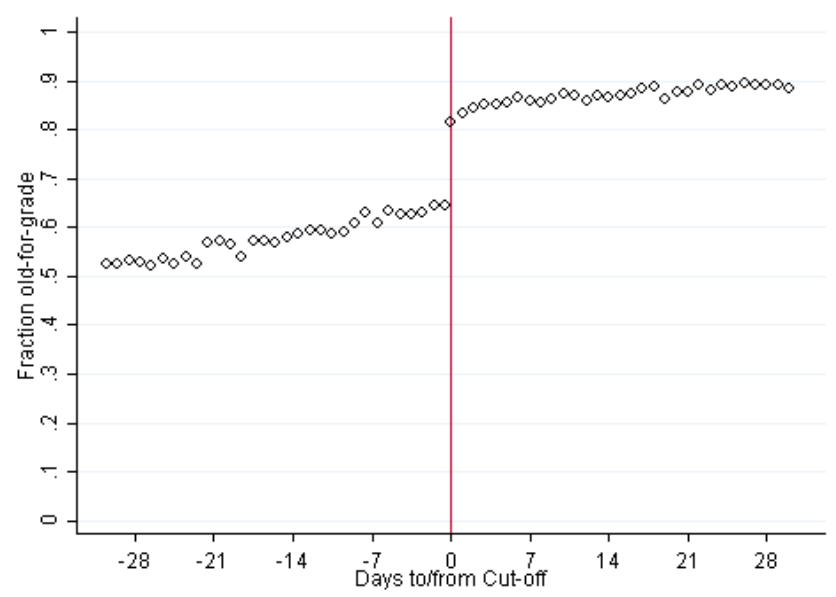

Figure 1

Fraction - Old-for-Grade by Date of Birth

Figure shows the fraction of "old-for-grade” children by date of birth around January 1 (marked by the vertical line). Being old-for-grade implies that the child starts school at age 7.6 instead of 6.6. Averages for population of children born in December or January from December 1986 to January 2000. 
A) Fraction in primary/lower secondary school (grades 1-10) by age

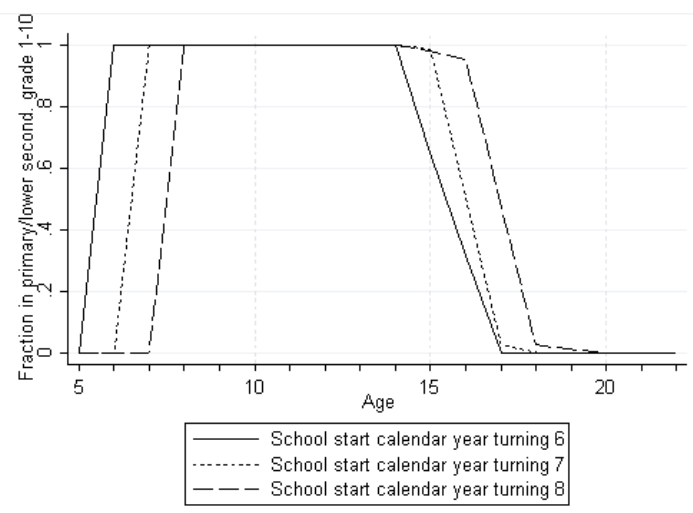

B) Fraction in upper secondary school by age

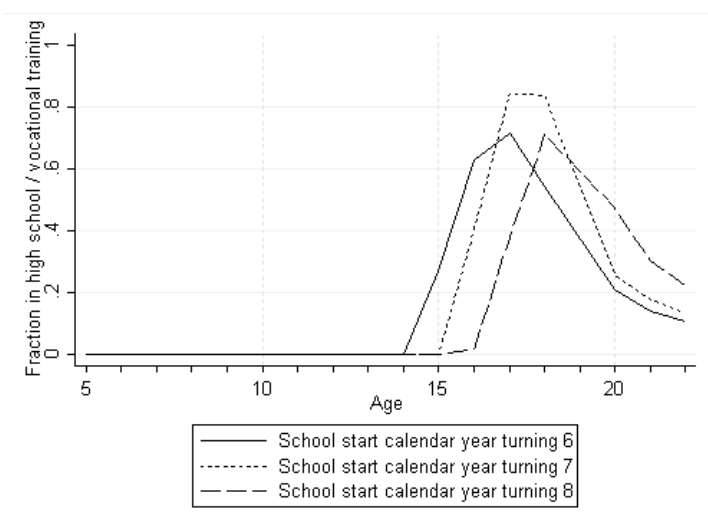

Figure 2

Enrollment into Education by SSA and Age

Figures show the fraction of children born 1986-2000 enrolled in education at each age by whether the child started school the calendar year they turned 6, 7 or 8 . Figure A shows the fraction of children enrolled in primary/lower secondary school, and Figure B shows the equivalent for enrollment into upper secondary school. 
A) Parents' time-use with child, by age of child

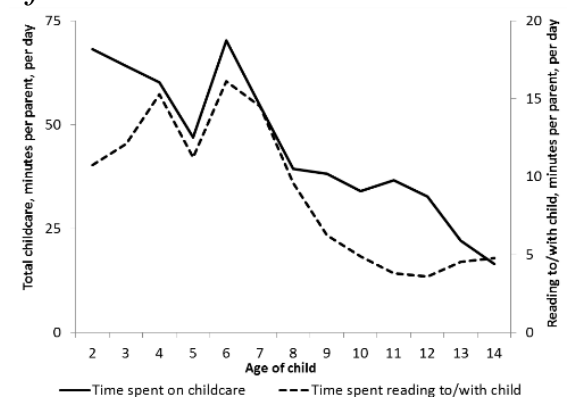

C) Maternal employment, by age of child

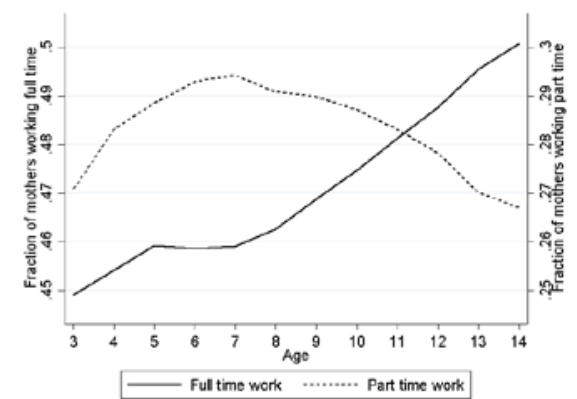

B) Activities done almost every day with child, by school start

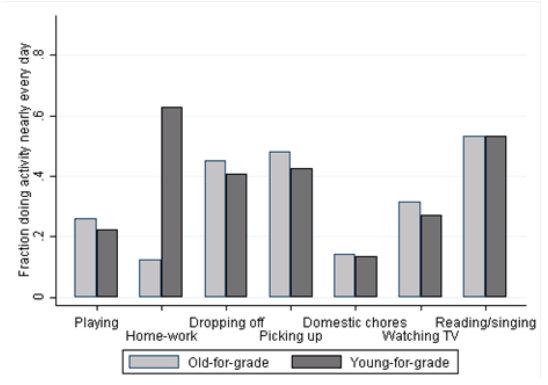

D) Time spent in out-of-home care or school, by school start

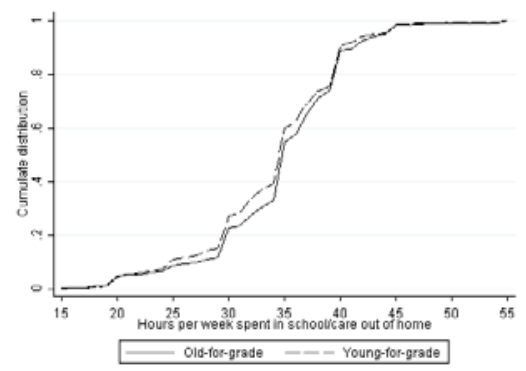

Figure 3

Time use of Parents and Children

Figure A shows average minutes spent per parent, per day, with the youngest child in the family on care and spare time activities (the solid line), and on reading to/with the child (the dashed line), across the age of the youngest child (own calculations based on the Danish Time Use and Consumption Survey 2008; see Bonke and Fallesen 2010). Figure B shows parental activities done almost every day, by whether their 7-year-old child has started school yet. The figure is constructed using the Danish Longitudinal Study of Children (DLSC). Figure C shows fraction of all mothers working full time and part time, respectively. The figure is constructed using monthly data from October (i.e. right after the start of an academic year) in the years 20082010, across children's age. Figure D shows difference in time spent in school or out-of-home care by whether the 7-year-old child has started school yet. The figure is based on DLSC. Young-for-grade implies that child is already in school; Old-for-grade implies that the child is not yet in school but only in Kindergarten. Observations: Figure A, 1,439; Figures B and D, 4,043; Figure C, 1,009,995 (238,808 individual children). 
A) 2SLS estimation results by focal child age

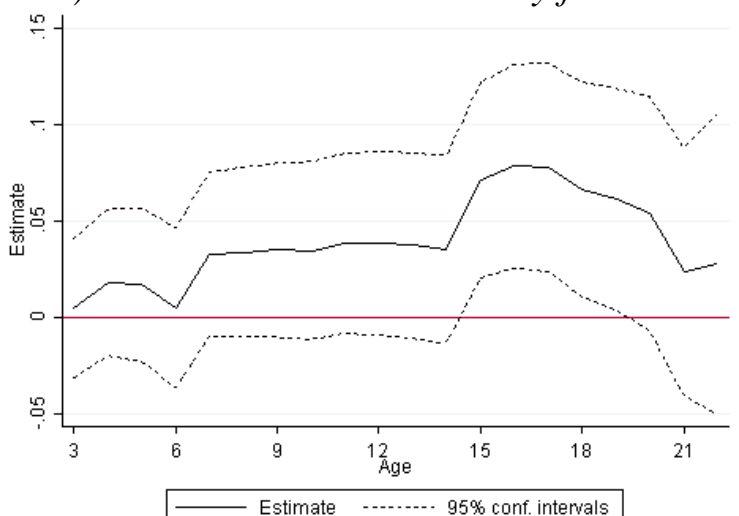

B) Compliers' counterfactual outcomes by focal child age

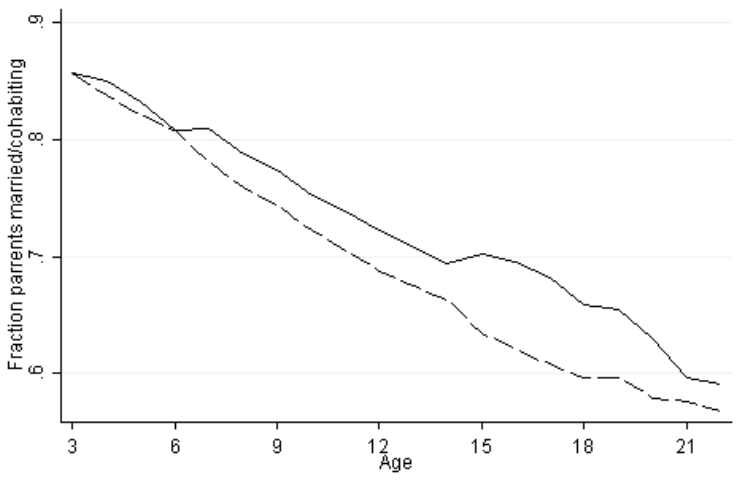

C) 2SLS estimation results by focal child's grade level

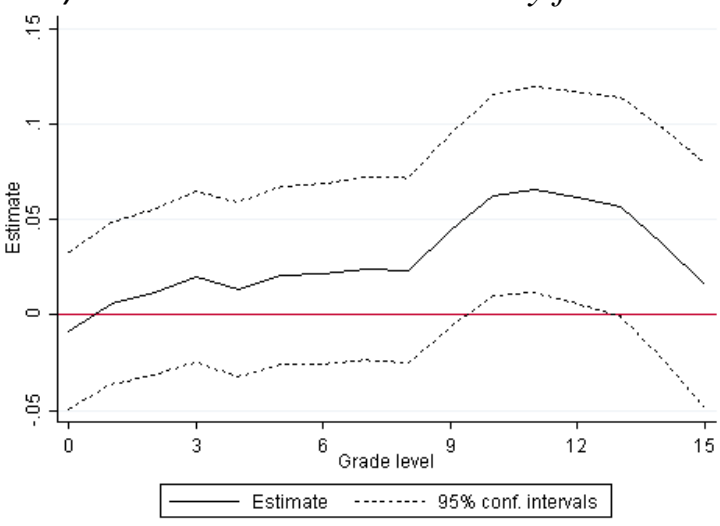

Figure 4

Parents Married or Cohabiting

Figure A shows the estimated effects of being old-for-grade on parents' relationship status across child's age from age 3-22 and Figure C shows estimates across grade level from grade 0-15 based on 2SLS regressions of fraction of parents who are married or cohabiting at a given age/grade. Cutoff dummy (January $=1)$ used as instrument. Conditioning set includes distance to cutoff, cohort fixed effects and background characteristics (see Table 2). Dashed lines 
indicate 95\% confidence intervals. Figure B shows the compliers' estimated counterfactual outcomes as in Abadie (2002) where the vertical distance between the two counterfactual outcomes corresponds to the points estimates shown in Figure A. Tables A5 and A6 show the estimates presented visually in Figures A and C. 
A) 2SLS estimation results by focal child age

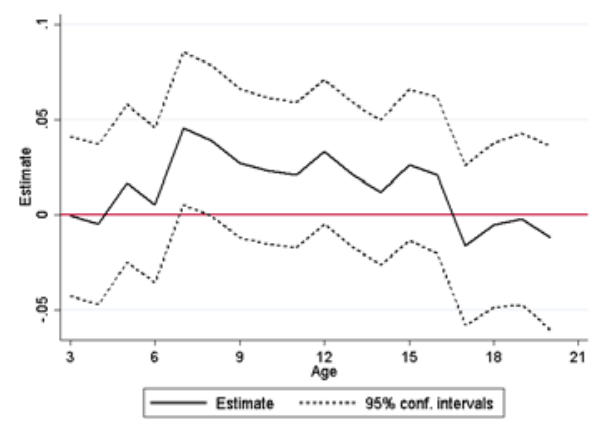

B) Compliers' counterfactual outcomes by focal child age

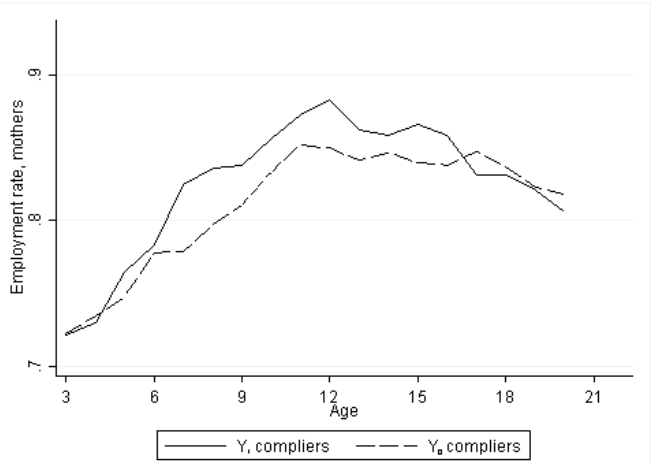

C) 2SLS estimation results by focal child's grade level

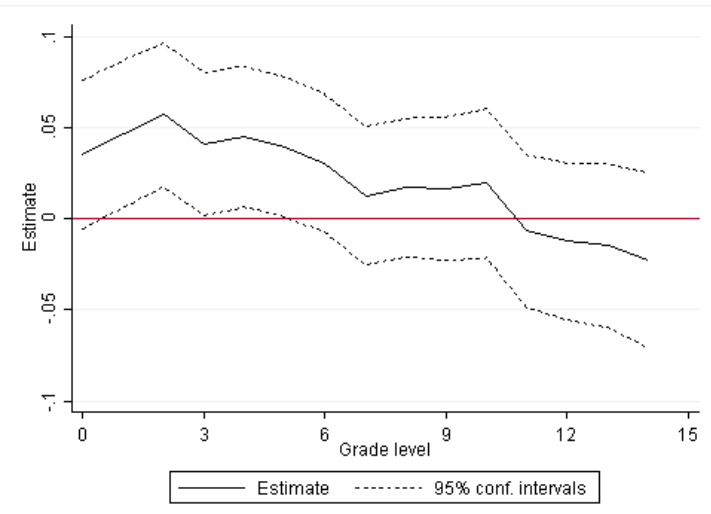

Figure 5

Maternal Employment

Figure A shows the estimated effects of being old-for-grade on maternal employment across child's age from age 3-22 and Figure C shows estimates across grade level from grade 0-15 based on 2SLS regressions of fraction of mothers in employment at a given age/grade. Cutoff dummy (January $=1$ ) used as instrument. Conditioning set includes distance to cutoff, cohort fixed effects and background characteristics (see Table 2). Dashed lines indicate 95\% 
confidence intervals. Figure B shows the compliers' estimated counterfactual outcomes as in Abadie (2002) where the vertical distance between the two counterfactual outcomes corresponds to the points estimates shown in Figure A. Tables A5 and A6 show the estimates presented visually in Figures A and C. 
A) Counterfactual cumulated wage earnings distribution, age 7

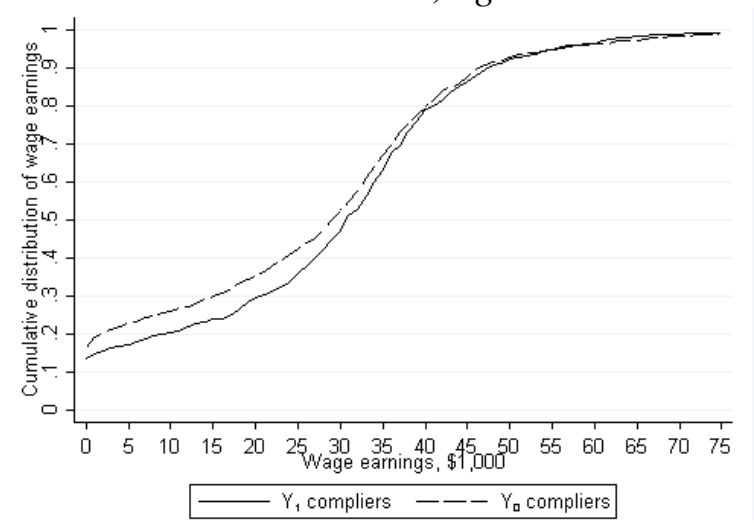

C) Counterfactual cumulated wage earnings distribution, age 8

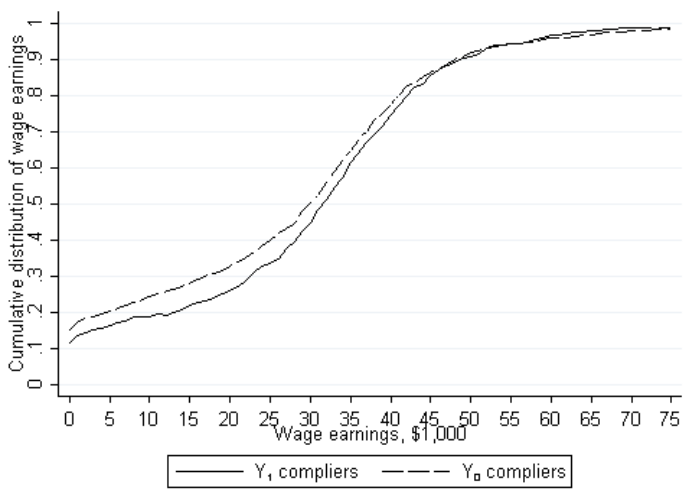

E) Counterfactual cumulated wage earnings distribution, age 9

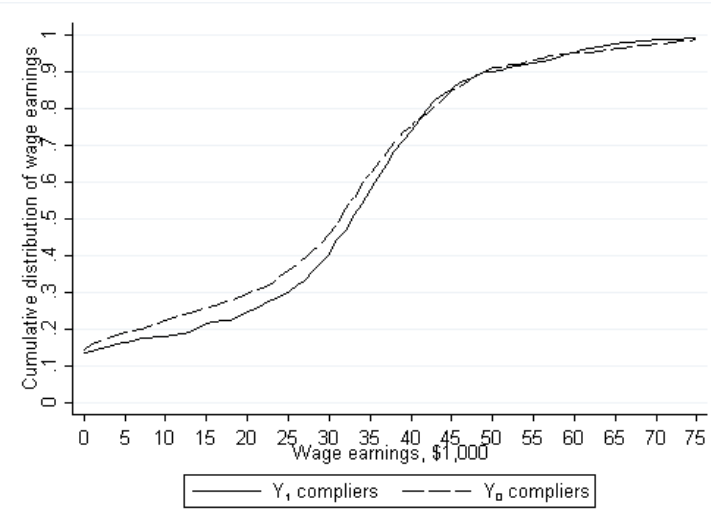

B) Change in density in wage earnings distribution, age 7

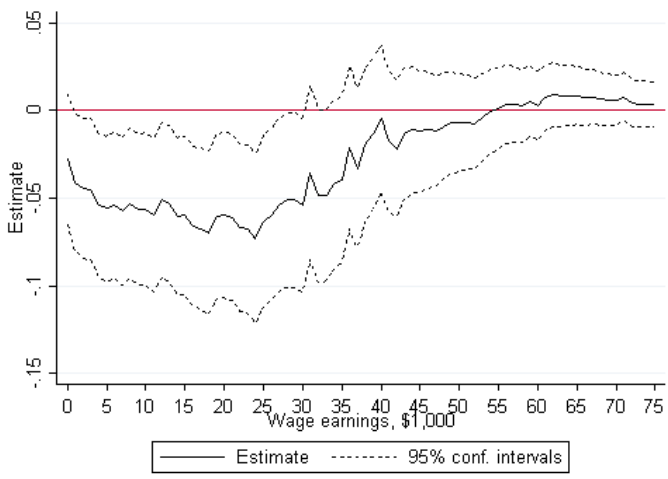

D) Change in density in wage earnings distribution, age 8

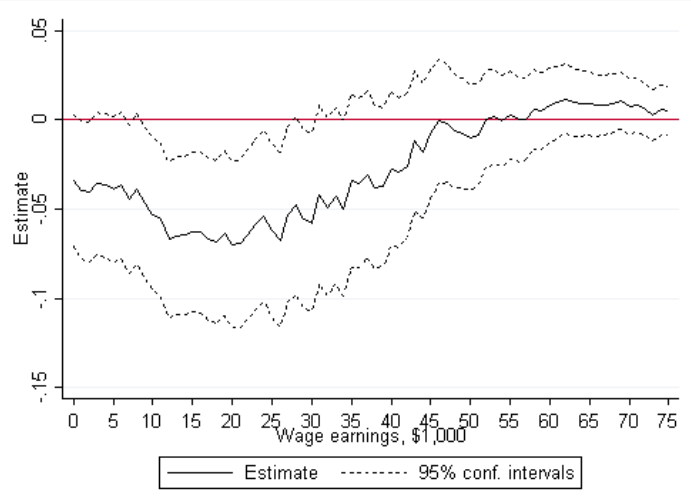

F) Change in density in wage earnings distribution, age 9

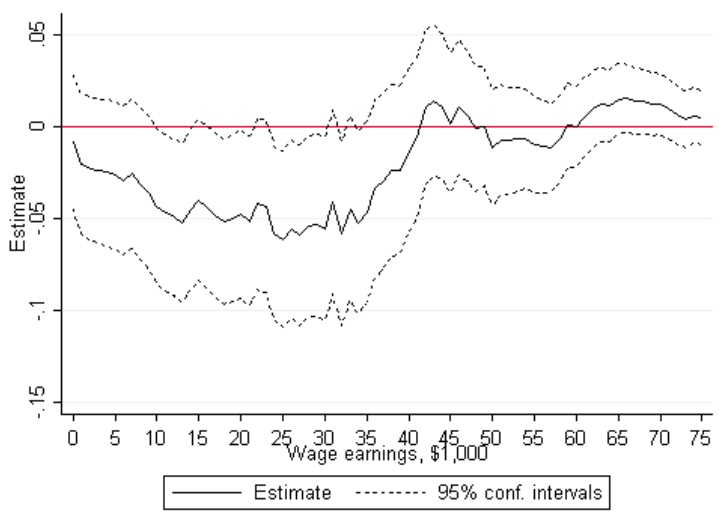

Figure 6

Effects of Being Old-for-Grade on Mother's Wage Earnings at Child Age 7, 8, and 9

Figures A, C, E show counterfactual cumulated wage earnings distributions of mothers of young-for-grade and old-for-grade children at child's age 7, 8, and 9, respectively. Figures B, $\mathrm{D}$, and $\mathrm{F}$ show the changes in densities across income levels induced by old-for-grade relative to being young-for-grade (the vertical differences between the lines in A, C, and E). Population: 
All mothers. Income measure: Annual earnings, year 2010 USD. Non-employed mothers have annual earnings equal to $\$ 0$. 
${ }^{1}$ This is to a lesser extent true in a US context, although US children have been enrolling in preschool at increasing rates as pointed out by Deming and Dynarski (2008).

${ }^{2}$ Females to a high extent choose careers which allow for such temporal flexibility because they are often secondary workers in the household. Furthermore, their careers are characterized by shorter hours and more career interruptions, which also explains part of the gender wage gap (e.g. Blau and Kahn 2017).

${ }^{3}$ Recent work indicates that parents may directly learn from their children; see Kuziemko (2014).

${ }^{4}$ SSA regulations are not strictly enforced and exemptions are granted based on applications from the parents. Exemptions are granted by the local municipality if considered beneficial for the child's development. School start can only be delayed by one year, and school is no longer compulsory from July 31 in the calendar year of the child's $17^{\text {th }}$ birthday, even if $9^{\text {th }}$ grade has not been completed. This is, however, not binding except in very few cases. School children do not pass or fail grades; in collaboration with the parents, the school principal can decide that a child repeats or jumps a grade if considered beneficial for the child’s development. For more details, consult the Danish Education Act.

${ }^{5}$ It is also possible to complete an elective $10^{\text {th }}$ grade before continuing on an academic or vocational path; an opportunity that approximately $50 \%$ of a cohort make use of (e.g., $52 \%$ of the cohort born in 1994 opted for $10^{\text {th }}$ grade).

${ }^{6}$ This is also denoted grade 0 .

${ }^{7}$ Opening hours are usually weekdays 6:30 am $-5 \mathrm{pm}$ (4:30 pm on Fridays) which facilitates that parents hold full-time jobs. A minimum of $67 \%$ of the expenses is covered by the local authorities (c.f. the Danish Children's Act).

${ }^{8}$ See Datta Gupta and Simonsen (2010). 
${ }^{9}$ Documented by Skolestartsudvalget (2006).

${ }^{10}$ Figure A1 illustrates this. The figure shows school starting age pattern across two cohorts by date of birth.

${ }^{11}$ This implies that approximately 65\% are "always-takers" (those who are old-for-grade even though they were born in late December) while roughly $15 \%$ are “never-takers” (those who are young-for-grade even though they are born in early January). In sum, this implies $80 \%$ non-compliance in the vicinity of the cutoff date. We discuss selective non-compliance in detail in Section V.F.

${ }^{12}$ Childcare includes activities with the primary purpose of doing something for the child or with the child. It includes both basic care and developmental care, and the purpose is to satisfy the needs or interests of the child.

${ }^{13}$ In the extreme, stressful experiences with one child could affect the choice to have additional children. We investigate this in our formal analyses and find no significant relationship.

${ }^{14}$ Manski (1993) identifies three reasons why individuals belonging to the same peer group, here their family, may tend to behave similarly. First, children's behavior may be influenced by the behavior of other siblings: endogenous effects. Second, a child's behavior may respond to the exogenous characteristics of the family: contextual effects. A third possibility is the presence of correlated effects in behavior that are unrelated to social interactions. This can occur if family members share similar observable or unobservable characteristics. The fundamental problem of separately identifying these three effects from one another is denoted the reflection problem. We rely on exogenous variation in school starting age to circumvent this problem.

${ }^{15} X$ includes child and parental characteristics predictive of SSA and outcomes: child gender, an indicator of low birth weight, low birth weight and child gender interacted, mother's age at 
the birth of child, father's age at the birth of child, number of siblings, whether parents are married / cohabiting measured before the birth of the child, and a flexible function of distance in days to the cutoff. In regressions for sibling outcomes, $X$ also includes sibling gender, an indicator of low birth weight of sibling and age distance to focal child.

${ }^{16}$ Our results are unaffected by the finding that children's season of birth is not random (Buckles and Hungerman, 2013), because our identification is based on variation in school starting age in a neighborhood around January 1.

${ }^{17}$ One factor that coincides with New Year is the timing of child benefits payments (paid to parents) because of the quarterly payment scheme. Children born on Dec 31 receive child benefits one quarter earlier compared to children born on Jan 1. Using a discount rate of 2\%, this has (for 2018 child benefits rates) a NPV of \$213 (in 2010 USD), and corresponds to $0.5 \%$ of the total benefits received until the child turns 18 . We therefore consider these incentives to manipulate children's date of birth miniscule. In line with this, the distribution of births (or caesarian sections) around New Year is entirely smooth.

${ }^{18}$ We discard all twins from the sample of children born around the cutoff in December and January but not from the sample of siblings.

${ }^{19}$ In practice this implies that we observe the treatment variable with measurement error. This will not affect results as long as the instrumental variable (the cutoff) is unrelated to this error. Landersø, Nielsen, and Simonsen (2017) validate our approach by exploiting more recent data with information about exact SSA to show that the measurement error does not vary across the cutoff.

${ }^{20}$ The patterns of parental labor force participation follow employment patterns closely, and therefore we do not study the former. Instead we discuss the extensive versus the intensive margins of the employment response, which are key in the Danish context. 
${ }^{21}$ Assessment of the smooth rise in maternal employment as children grow older is the focus of Lubotsky and Qureshi (2018). They downplay standard explanations such as falling childcare costs, changing non-labor income and family dissolution. Instead they argue that some potential reasons for the smooth rise in employment are that older children require less supervision and that time spent with them is less exhausting. These explanations are consistent with the mechanisms studied in this paper.

${ }^{22}$ All tables and figures numbered “ $\mathrm{A}$ *” are found in the Online Appendix at http://jhr.uwpress.org/.

${ }^{23}$ For children born in December 1986 or January 1987, we use parental characteristics measured in 1985, whereas for children born in December 1987 or January 1988 we use parental characteristics measured in 1986 etc.

${ }^{24}$ This is different from the US context (see Deming and Dynarski, 2008).

${ }^{25}$ A recent paper by Young (2017) points to issues with the quality of inference in IV analyses. Exploiting about 1,400 two stage least squares regressions from 32 papers, he argues that IV methods rarely identify parameters more accurately than does OLS. This is to some extent driven by weak instruments but primarily by departure from the iid normal ideal. In our case, where the instrumental variation is driven by birthdate and the treatment occurs at the individual level, we are less concerned about issues such as clustering. Heteroscedasticity is another issue raised by Young (2017), yet we detect highly significant differences in the first stages across subgroups. Moreover, our particular instrument has independently been shown to work across numerous settings.

${ }^{26}$ One concern that might change the interpretation of our results throughout the paper is if the focal child's SSA is related to the subsequent birth of siblings (i.e. fertility). We have studied this relationship, which could introduce additional shocks to parents' investments and time-use. The results are shown in Table A4. We find that preceding (upper part of table) and 
subsequent fertility (lower part of table) are not significantly related to the focal child's SSA, which supports our interpretation of the results presented below.

${ }^{27}$ Figure A6.A in the Online Appendix shows the corresponding reduced form scatterplot at child age 15.

${ }^{28}$ Results on parental relationship status and maternal employment are robust to extending bandwidth to \pm 45 days instead of \pm 30 days around New Year; see Figure A7. Figure A8 shows the effects by gender. Overall, the results are qualitatively similar, but the maternal employment effects are marginally stronger for boys.

${ }^{29}$ This is in line with Blau and Kahn (2017) who find that the temporal flexibility of women in terms of career interruptions and shorter hours play an important role for the gender gap. This suggests that women react to constraints within the household by adjusting their labor market activity.

${ }^{30}$ Previous research has studied the relationship between childcare and maternal employment. This literature has focused on the impact of childcare subsidies and eligibility on maternal employment and found mixed results across contexts (see Gelbach 2002, Havnes and Mogstad 2011, Fitzpatrick 2012, Cascio, Haider, and Nielsen 2015). Our study differs from previous research in that our two counterfactual treatment states both involve low-cost/highquality out-of-home care/education. Thus our result cannot be attributed to childcare costs or eligibility. Instead, we interpret our results as indicative of family spillovers.

${ }^{31}$ Full-time employment for low-skilled (e.g. cleaning assistants) at the average minimum wage between sectors corresponds to an annual income of approximately $\$ 25,000$, whereas full-time employment for high-skilled (e.g. nurses) corresponds to approximately $\$ 40,000$. As we see effects mainly for low skilled mothers, the shift from wage earnings between \$120,000 to $\$ 20-40,000$ thus corresponds to a shift from part-time to full- time employment. 
${ }^{32}$ Two notes of caution are appropriate here. Almost 70\% of mothers with education beyond high school have a partner who also has a higher education. If child inputs of high-educated parents more often complement each other compared to low-educated parents, this would ease the constraints in such families. Furthermore, the group of compliers may vary with maternal education, which complicates direct comparisons. However, the same pattern is seen when we divide the sample according to the place in the earnings distribution (results not reported).

${ }^{33}$ We do not report estimates by family size, as this would impose a selection on parents' marital stability (i.e. selection on an outcome variable). Parents can only have more children if they stay together, while separations are more frequent among parents who only have one child (and therefore do not have any more children together).

${ }^{34}$ Widely spaced siblings tend to have parents with lower employment and marriage rates, and these siblings also have below-mean test scores. Parents of closely spaced siblings have higher employment and marriage rates, and the siblings have above-mean test scores. These differences likely reflect that the parents of widely spaced siblings tend to have had their first child at an earlier age - an attribute that is negatively associated with own and children's outcomes.

${ }^{35}$ Table A8 in the Online Appendix reveals some gender heterogeneity in point estimates. For older brothers, point estimates are significantly positive when the age distance is below 3 years. This suggests that some boys may be vulnerable during the first years in school and therefore benefit from younger siblings being old-for-grade.

${ }^{36}$ Table A9 in the Online Appendix revisits these results using smaller samples that are balanced in terms of the distribution of age distance between siblings across calendar time.

37 See Bloom (1956).

${ }^{38}$ However, one must exert caution when comparing families across maternal education. 